Article

\title{
Catalytic and Sulfur-Tolerant Performance of Bimetallic Ni-Ru Catalysts on HI Decomposition in the Sulfur-Iodine Cycle for Hydrogen Production
}

\author{
Lijian Wang ${ }^{1}{ }^{(D)}$, Kang Zhang ${ }^{2, *}$, Yi Qiu ${ }^{1}$, Huiyun Chen ${ }^{1}$, Jie Wang ${ }^{1}$ and Zhihua Wang ${ }^{3 \oplus}$ \\ 1 Zhejiang Institute of Metrology, Hangzhou 310018, China; 3100103014@zju.edu.cn (L.W.); \\ qiuyi@zju.edu.cn (Y.Q.); taoyikun@gzrobot.com (H.C.); 11427033@zju.edu.cn (J.W.) \\ 2 State Grid Zhejiang Electric Power Research Institute, Hangzhou 310014, China \\ 3 State Key Laboratory of Clean Energy Utilization, Zhejiang University, Hangzhou 310027, China; \\ wangzh@zju.edu.cn \\ * Correspondence: zhangkang@zju.edu.cn; Tel.: +86-183-6815-5130
}

\section{check for}

updates

Citation: Wang, L.; Zhang, K.; Qiu, Y.; Chen, H.; Wang, J.; Wang, Z. Catalytic and Sulfur-Tolerant Performance of Bimetallic Ni-Ru Catalysts on HI Decomposition in the Sulfur-Iodine Cycle for Hydrogen Production. Energies 2021, 14, 8539. https://doi.org/10.3390/en14248539

Academic Editors: Vladislav

A. Sadykov and

George Avgouropoulos

Received: 15 October 2021

Accepted: 14 December 2021

Published: 17 December 2021

Publisher's Note: MDPI stays neutral with regard to jurisdictional claims in published maps and institutional affiliations.

Copyright: (c) 2021 by the authors. Licensee MDPI, Basel, Switzerland. This article is an open access article distributed under the terms and conditions of the Creative Commons Attribution (CC BY) license (https:/ / creativecommons.org/licenses/by/ $4.0 /)$.

\begin{abstract}
The sulfur-iodine (SI) cycle holds great promise as an alternative large-scale process for converting water into hydrogen without $\mathrm{CO}_{2}$ emissions. A major issue regarding the long-term stability and activity of the catalysts is their poor sulfur deactivation resistance in the HI feeding process. In this work, the effect of Ru addition for enhancing the activity and sulfur resistance of $\mathrm{SiO}_{2}$-supported $\mathrm{Ni}$ catalysts in the $\mathrm{HI}$ decomposition reaction has been investigated. The presence of $\mathrm{H}_{2} \mathrm{SO}_{4}$ molecules in the $\mathrm{HI}$ results in severe sulfur deactivation of the $\mathrm{Ru}$-free $\mathrm{Ni} / \mathrm{SiO}_{2}$ catalysts by blocking the active sites. However, $\mathrm{Ni}-\mathrm{Ru} / \mathrm{SiO}_{2}$ catalysts show higher catalytic activity without sulfur-poisoning by $25 \%$ and exhibit more superior catalytic performance than the Ru-free catalyst. The addition of $\mathrm{Ru}$ to the $\mathrm{Ni} / \mathrm{SiO}_{2}$ catalyst promotes the stability and activity of the catalysts. The experimental trends in activity and sulfur tolerance are consistent with the theoretical modeling, with the catalytic activities existing in the order $\mathrm{Ni} / \mathrm{SiO}_{2}<\mathrm{Ni}-\mathrm{Ru} / \mathrm{SiO}_{2}$. The effect of $\mathrm{Ru}$ on the improvement in sulfur resistance over Ni-based catalysts is attributed to electronic factors, as evidenced by theory modeling analysis and detailed characterizations.
\end{abstract}

Keywords: hydrogen production; SI cycle; HI decomposition; bimetallic catalysts; sulfur-tolerant

\section{Introduction}

Hydrogen is considered as an environment-friendly fuel and sustainable energy vector. Due to its good thermal efficiency and operability, various important efforts have been made to promote hydrogen production via the thermochemical sulfur-iodine (SI) cycle [1-9]. The SI cycle consists of the following reactions [10]:

$$
\begin{aligned}
& \mathrm{SO}_{2}(\mathrm{~g})+\mathrm{I}_{2}(\mathrm{~s})+2 \mathrm{H}_{2} \mathrm{O}(\mathrm{l}) \stackrel{293-393}{\leftrightarrow} \mathrm{K}^{2} \mathrm{H}_{2} \mathrm{SO}_{4}(\mathrm{aq})+2 \mathrm{HI}(\mathrm{aq}) \\
& 2 \mathrm{HI}(\mathrm{g}) \stackrel{573-773 \mathrm{~K}}{\leftrightarrow} \mathrm{H}_{2}(\mathrm{~g})+\mathrm{I}_{2}(\mathrm{~g}) \\
& \mathrm{H}_{2} \mathrm{SO}_{4}(\mathrm{~g}) \stackrel{873-1173 \mathrm{~K}}{\leftrightarrow} \mathrm{SO}_{2}(\mathrm{~g})+\mathrm{H}_{2} \mathrm{O}(\mathrm{g})+1 / 2 \mathrm{O}_{2}(g)
\end{aligned}
$$

In Reaction (1) (Bunsen reaction), iodine from reaction (2) reacts with sulfur dioxide and water to generate sulfuric acid and hydrogen iodide. The products of Bunsen reaction are a mixture of $\mathrm{H}_{2} \mathrm{SO}_{4}$, hydrogen iodide $(\mathrm{HI})$, and $\mathrm{H}_{2} \mathrm{O}$. The mixture is required to be separated, thus processing the thermal decompositions of the two acids. Herein, two non-miscible acidic phases (sulfuric acid and the $\mathrm{HI}_{\mathrm{x}}$ phase) can be produced with an excess of iodine and water [11]. Accordingly, the two acidic phases are purified via a reverse Bunsen reaction at $423 \mathrm{~K}$, and the purified $\mathrm{HI}$ is then catalytically dissociated into $\mathrm{H}_{2}$ and $\mathrm{I}_{2}$ at $573-773 \mathrm{~K}$. The purified $\mathrm{H}_{2} \mathrm{SO}_{4}$ decomposes into $\mathrm{O}_{2}, \mathrm{H}_{2} \mathrm{O}$, and $\mathrm{SO}_{2}$ at about 
$1073 \mathrm{~K}$. The products from Reaction (2) and Reaction (3) can be entirely recycled in the SI cycle, except the $\mathrm{H}_{2}$ and $\mathrm{O}_{2}$.

Consequently, the net reaction of the SI cycle is complete water decomposition at relatively low temperatures. Reaction (2) is the key reaction, and it is hard to proceed without the help of a catalyst, even at $773 \mathrm{~K}$, due to the relatively low homogeneous gas-phase conversion rate (only $2.2 \%$ at $773 \mathrm{~K}$ ). Therefore, numerous $\mathrm{HI}$ decomposition catalysts have been studied to increase the conversion rate of $\mathrm{HI}$ decomposition.

Up to now, various catalysts have been assessed for use in the catalytic decomposition of $\mathrm{HI}$, including noble metal elements $(\mathrm{Pt}, \mathrm{Au}, \mathrm{Ru}, \mathrm{Ag})[12,13]$, transition metals (Ni, Ce) [14-16], and activated carbon catalysts [17]. Among these, Pt, Ni, and Co loaded on $\mathrm{CeO}_{2}$ support have shown significant promise. The $\mathrm{Pt} / \mathrm{CeO}_{2}$ has the best, and $\mathrm{Co} / \mathrm{CeO}_{2}$ has the worst catalytic performance [18-20]. The effect of catalysts prepared by loading $\mathrm{Ni}$ onto different carbon materials has also been addressed, including Ni/MWCNT, Ni/CMS, $\mathrm{Ni} / \mathrm{AC}$, and Ni/GNP [21]. The activity performance and lifespan evaluation of $\mathrm{Ni} / \gamma$ $\mathrm{Al}_{2} \mathrm{O}_{3}$ catalysts in $\mathrm{HI}$ decomposition have been determined at $773 \mathrm{~K}$ [22]. The catalytic kinetics of spheroidal activated carbon have also been studied, and the spherical activated carbon was stable at $140 \mathrm{~h}$ [23].

Much research on mechanism analyses has been conducted to develop a suitable and inexpensive catalyst for HI decomposition [24-26]. Nevertheless, sulfur-containing compounds have been previously observed in the iodidric solution $[7,9,27-30]$. Sulfur poisoning is one of the most critical factors in catalytic deactivation [31,32]. To the best of our knowledge, no current studies are focusing on the improvement of sulfur tolerance for $\mathrm{HI}$ decomposition. Consequently, it is essential to evaluate the deactivation mechanism from sulfur poisoning and reduce the presence of sulfur species on the catalyst. Ru is an active noble catalytic component, and the combination of $\mathrm{Ni}$ and $\mathrm{Ru}$ has been observed to perform multiple roles [33]. As far as we know, Ni-Ru catalysts have not been reported for use in the SI cycle. Therefore, this study synthesized Ni-Ru bimetallic catalysts and examined the catalytic activity and sulfur tolerance performance of $\mathrm{Ni}$ and $\mathrm{Ni}-\mathrm{Ru}$ catalysts supported on $\mathrm{SiO}_{2}$ in $\mathrm{HI}$ decomposition reactions.

\section{Experimental Methodology}

\subsection{Catalyst Preparation}

All the chemicals in this study were analytical-grade reagents. The silicon dioxide (Aladdin Reagent Co., Ltd., Shanghai, China) was dried at $393 \mathrm{~K}$ for $2 \mathrm{~h}$ and then calcined in air at $973 \mathrm{~K}$ for $5 \mathrm{~h}$ before use. The nickel nitrate hexahydrate $(5.60 \mathrm{~g})$, ruthenium nitrosyl nitrate $(0.48 \mathrm{~g})$, and polyethylene glycol $(5.86 \mathrm{~g}$, average molecular weight $=1000)$ were dissolved in the solution of solvent containing $300 \mathrm{~mL}$ of deionized water and $100 \mathrm{~mL}$ of butanol. The mixture was refluxed at $393 \mathrm{~K}$ in an oil bath under vigorous stirring for $2 \mathrm{~h}$. Then, $10 \mathrm{~g}$ of $\mathrm{SiO}_{2}$ was introduced with continuous stirring. The formed suspensions were evaporated at $393 \mathrm{~K}$, until the solvent was removed and a paste-like sample formed. The sample was dried in an oven at $393 \mathrm{~K}$ for $12 \mathrm{~h}$ and subsequently calcined in air at $673 \mathrm{~K}$ for $5 \mathrm{~h}$ to prepare the supported $\mathrm{Ni}-\mathrm{Ru} / \mathrm{SiO}_{2}$ metal oxides. The mass percentage of $\mathrm{Ni}$ in the $\mathrm{Ni}-\mathrm{Ru} / \mathrm{SiO}_{2}$ was $10 \mathrm{wt} \%$. The samples were first reduced for $2 \mathrm{~h}$ in a hydrogen atmosphere at $873 \mathrm{~K}$. Subsequently, the samples were passivated at room temperature in an atmosphere of $1 \%$ oxygen. The monometallic $\mathrm{Ni} / \mathrm{SiO}_{2}$ catalyst $(10 \mathrm{wt} \% \mathrm{Ni})$ was produced via the same preparation method without adding ruthenium nitrosyl nitrate. The $\mathrm{Ni}$ and $\mathrm{Ni}-\mathrm{Ru}$ were supported on $\mathrm{SiO}_{2}$, and defined as $\mathrm{Ni} / \mathrm{SiO}_{2}$ and $\mathrm{Ni}-\mathrm{Ru} / \mathrm{SiO}_{2}$. These catalysts were pressed, crushed, and then sieved into 60-80 mesh particles.

\subsection{Characterization}

The morphology and elemental compositions of the catalysts were characterized using a transmission electron microscope (TEM) equipped with energy-dispersive $\mathrm{X}$-ray spectroscopy (EDX) on a JEM-2010-HR (JEOL Ltd., Tokyo, Japan). The catalyst powders were ground and then coated on the surface of copper grids with ethanol. The framework 
structure of the catalysts was assessed using the X-ray diffraction (XRD) technique with a Rigaku K/max2550/PC (Rigaku Corporation, Tokyo, Japan) diffractometer at $40 \mathrm{kV}$ and $100 \mathrm{~mA}$ (step time of $0.02 \mathrm{~s}$ and step size of $0.02^{\circ}$ ). X-ray photoelectron spectroscopy (XPS) analyses were performed on an Escalab 250Xi system (Thermo Scientific Ltd., Bedford, MA, USA) with MgK $\alpha$ radiation under ultra-high vacuum conditions $\left(5 \times 10^{-8} \mathrm{~Pa}\right)$. Temperature programmed reduction (TPR) was carried out with an AutoChem II 2920 automated catalyst characterization system (Micromeritics Instrument Corporation, Norcross, GA, USA). At the end of $\mathrm{HI}$ decomposition tests, the catalysts $\mathrm{Ni} / \mathrm{SiO}_{2}$ and $\mathrm{Ni}-\mathrm{Ru} / \mathrm{SiO}_{2}$ were cooled to room temperature, discharged from the fixed-bed reactor, and then transferred to XRD and XPS studies. In this case no precautions were taken to prevent exposure of the catalysts to air prior to the XRD and XPS analysis.

\subsection{Catalyst Activity and Stability Test}

The catalytic activity and sulfuric acid poisoning process were conducted in a flow fixed-bed reactor, as described in Figure 1. An automated system was installed to produce $\mathrm{H}_{2}$ from an $\mathrm{HI}$ decomposition reaction. A mass-flow controller and syringe pump were used to control the flow of the carrier gases. The fixed-bed reactor consists of an electric heater and a silica tube (18 $\mathrm{mm}$ in inner diameter $\times 458 \mathrm{~mm}$ in length). A type $\mathrm{K}$ thermocouple was equipped to monitor the reaction temperature in the middle of the catalysts bed. $0.5 \mathrm{~g}$ of catalyst, mixed uniformly with coarse quartz particles, was fed into the fixed-bed reactor. The feeding rate of hydroiodic acid ( $55 \mathrm{wt} \%$ at different concentrations of sulfuric acid) into the evaporator $(433 \mathrm{~K})$ was $0.5 \mathrm{~mL} / \mathrm{min}$ and controlled via a syringe pump. $60 \mathrm{~mL} / \mathrm{min} \mathrm{N}_{2}$ was used to drive the vaporized HI. A stream of gaseous mixture subsequently entered the fixed-bed reactor. After the HI decomposition reaction, the mixed gases passed through a gyroidal water condenser, several $\mathrm{NaOH}$ solution absorbers, and silica gels, accomplishing the purification of residual $\mathrm{H}_{2}$ and $\mathrm{N}_{2}$. The outlet gases were collected and analyzed using a hydrogen analyzer.

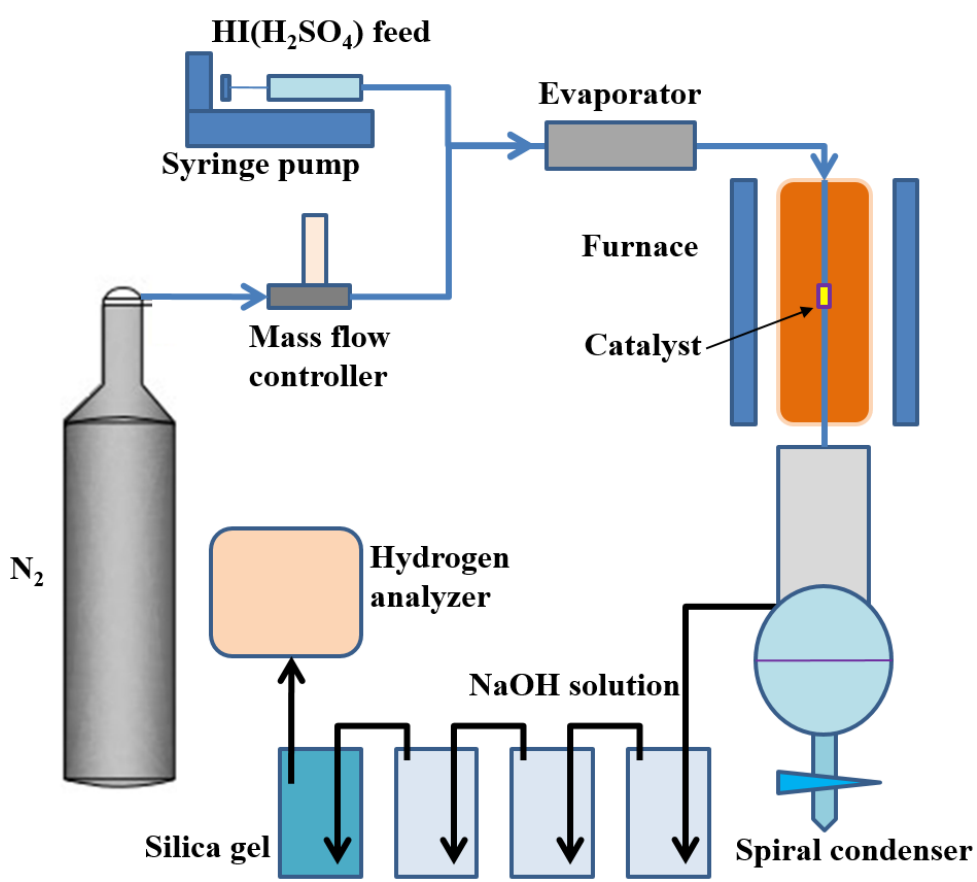

Figure 1. Schematic of the test facility for assessing catalytic activity and poisoning.

The HI conversion can be expressed by the following equation:

$$
\alpha=\frac{2 \mathrm{ND}}{\operatorname{Rn}(1-\mathrm{D})}
$$


where $\alpha$ is the value of $\mathrm{HI}$ conversion. $\mathrm{D}$ denotes hydrogen concentration. $\mathrm{R}$ is the molar volume constant of gas. $\mathrm{N}$ is the volume flow rate of driving gas $\left(\mathrm{N}_{2}\right)$, and $\mathrm{n}$ is the molar flow rate of $\mathrm{HI}$ solution.

The deactivation ratio can be expressed by following equation:

$$
\beta=\frac{1-\alpha_{i}}{\alpha_{0}} \times 100 \%
$$

where $\beta$ is the value of deactivation ratio. $\alpha_{0}$ denotes $\mathrm{HI}$ conversion in a standard HI decomposition step with an $\mathrm{HI}$ solution ( $55 \mathrm{wt} \%$ ) in the absence of $\mathrm{H}_{2} \mathrm{SO}_{4} . \alpha_{\mathrm{i}}$ is the HI conversion in poisoning step with a solution at different $\mathrm{H}_{2} \mathrm{SO}_{4}$ concentrations, and $\mathrm{i}$ denotes poisoning steps at different $\mathrm{H}_{2} \mathrm{SO}_{4}$ concentrations.

\subsection{Theoretical Modeling}

The different adsorption energies of $\mathrm{HI}$ and $\mathrm{S}$ on various Ni-Ru clusters were assessed by the Vienna Ab-initio Simulation Package (VASP) [34,35], using the density functional theory (DFT) and the Projected Augmented Wave (PAW) methods [36]. The Perdew-BurkeErnzerhof (PBE) function was used to express the exchange and correlation effect [37]. For all geometry optimizations, the cutoff energy was set to be $450 \mathrm{eV}$. Spin-polarization was included in the calculations of Ni-containing groups. The simulation models were constructed in a $19 \AA \times 19 \AA \times 19 \AA$ box, which is sufficient to eliminate the influence of neighboring clusters. The Monkhorst-Pack grids were set to be $1 \times 1 \times 1$ for all calculations [38].

The adsorption energy of $\mathrm{HI}$ and $\mathrm{S}$ on the $\mathrm{Ni}-\mathrm{Ru}$ clusters was defined as:

$$
\Delta E_{a d s}=E_{a d s}-E_{s l a b}-E_{H I(S)}
$$

where $E_{a d s}$ is the electronic energy of the cluster with an adsorbed $H I$ or $S, E_{\text {slab }}$ is the electronic energy of the clean cluster, and $E_{H I(S)}$ is the electronic energy of one $H I$ or $S$. The electronic energy of one $S$ atom was referenced as the energy of one $S_{8}$ cluster. Under this definition, a more negative value indicated a stronger binding.

\section{Results and Discussion}

\subsection{Properties of the Catalysts}

As shown in Figure 2, the diffraction patterns of fresh $\mathrm{Ni} / \mathrm{SiO}_{2}$ and $\mathrm{Ni}-\mathrm{Ru} / \mathrm{SiO}_{2}$ catalysts exhibit similar typical peaks. The pattern for the supports is that of crystallized materials with wide diffraction peaks in the $2 \theta$ range between 15 and 30, which are features of amorphous silica. Additionally, three diffraction peaks around 44.5, 51.85 and 76.37 are ascribed to the (111), (200) and (220) planes of the cubic structure of Ni [JCPDS No. 04-0850]. The presence of only metallic nickel in the XRD analyses indicates that most $\mathrm{NiO}$ phases are reduced to form metallic Ni during the pre-reduction of the catalyst, which may have been active for HI decomposition. No significant diffraction peak of Ru is detected in the $\mathrm{Ni}-\mathrm{Ru} / \mathrm{SiO}_{2}$ catalysts. These results suggest that the $\mathrm{Ru}$ is well dispersed on the $\mathrm{SiO}_{2}$. The particle size of $\mathrm{Ru}$ is very small, and the dispersion of the granules is homogeneous.

The TEM micrographs are used to observe the sizes and morphologies of the species on the catalysts. As shown in Figure 3, the fresh $\mathrm{Ni}-\mathrm{Ru} / \mathrm{SiO}_{2}$ catalysts are investigated by TEM-EDX. It is noted that the nickel and ruthenium particles are small and homogeneously dispersed on the $\mathrm{SiO}_{2}$ surface. Further EDX analysis of the $\mathrm{Ni}-\mathrm{Ru} / \mathrm{SiO}_{2}$ catalysts are used to characterize the particles on the catalysts, as shown in Figure 3b. The $\mathrm{Ni}, \mathrm{Ru}, \mathrm{O}$, and $\mathrm{Si}$ elements are clearly deposited. These observations suggested that the bimetallic $\mathrm{Ni}-\mathrm{Ru}$ species are spread on the $\mathrm{Ni}-\mathrm{Ru} / \mathrm{SiO}_{2}$ catalysts. 


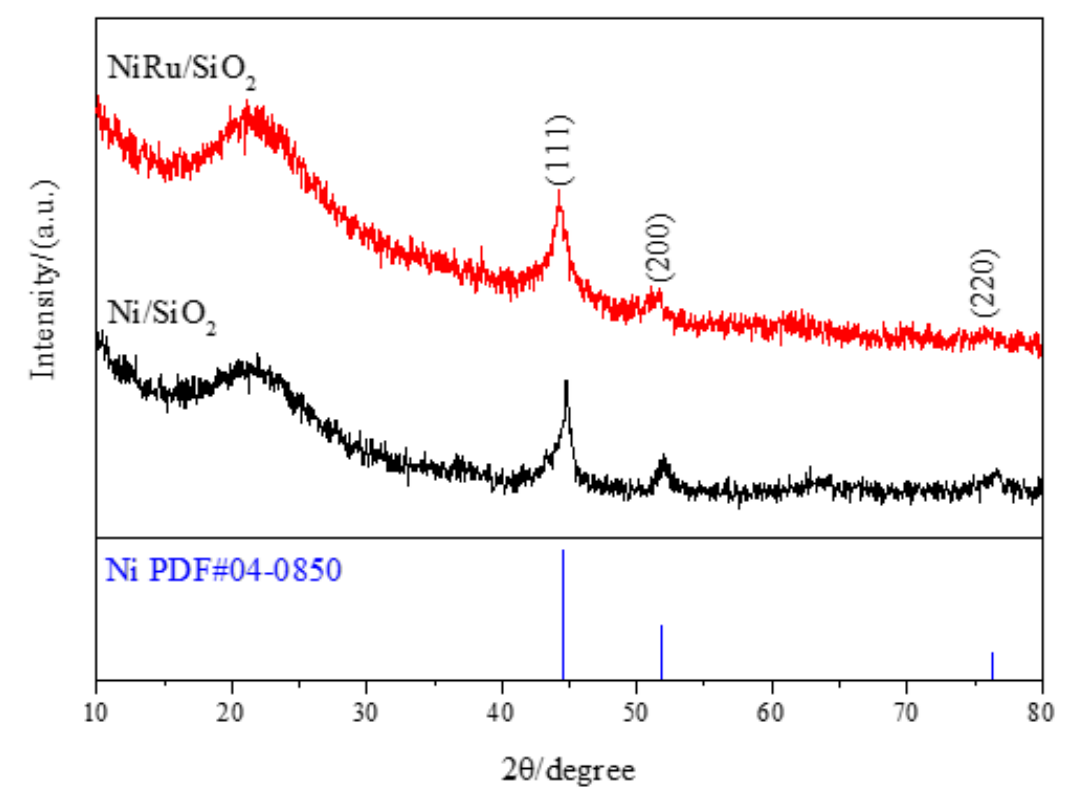

Figure 2. XRD patterns of the fresh $\mathrm{Ni} / \mathrm{SiO}_{2}$ and $\mathrm{Ni}-\mathrm{Ru} / \mathrm{SiO}_{2}$ catalysts.
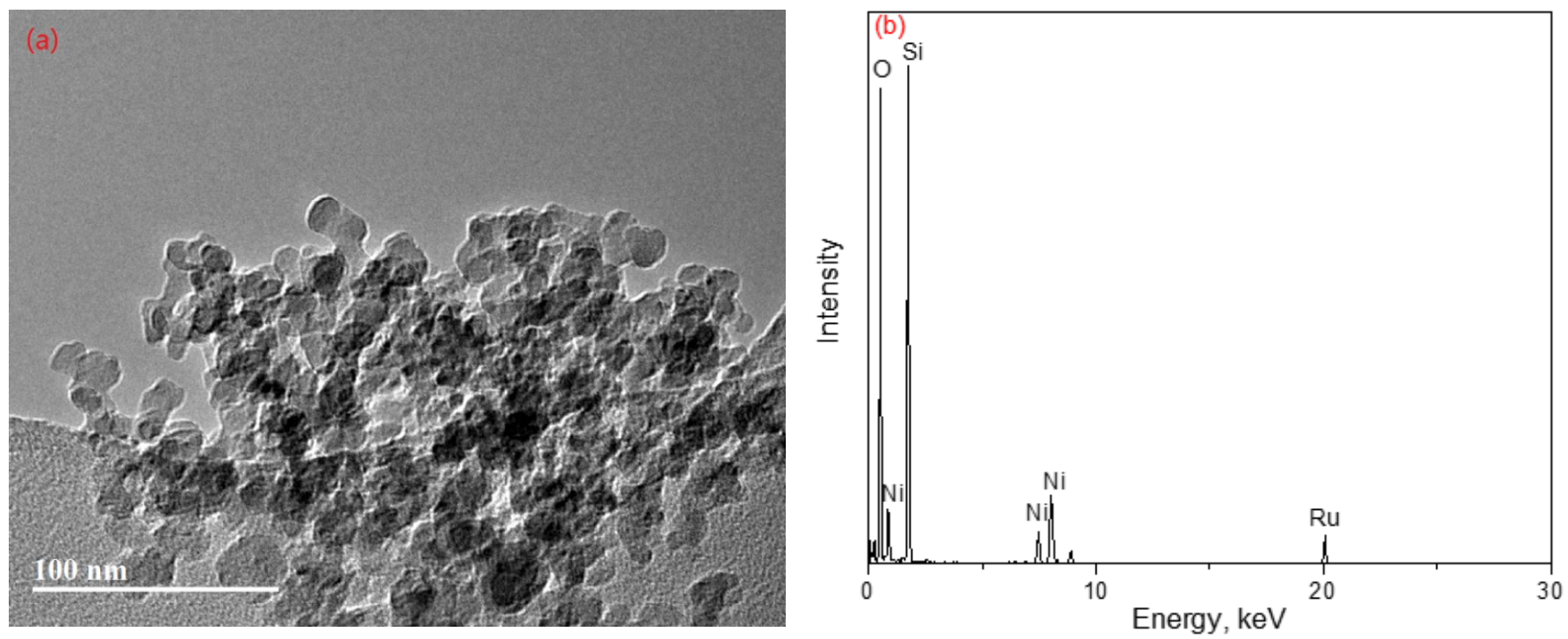

Figure 3. TEM-EDX analysis of the $\mathrm{Ni}-\mathrm{Ru} / \mathrm{SiO}_{2}$ catalysts: (a) TEM photo; (b) EDX signature.

The TPR profiles of the $\mathrm{Ni} / \mathrm{SiO}_{2}$ and $\mathrm{Ni}-\mathrm{Ru} / \mathrm{SiO}_{2}$ samples are shown in Figure 4 . For the $\mathrm{Ni} / \mathrm{SiO}_{2}$ catalyst, a large hydrogen-consuming peak at $562 \mathrm{~K}$ accompanied by an obvious shoulder between 650 and $850 \mathrm{~K}$ is observed. The former reduction peak can be ascribed to the reduction of $\mathrm{NiO}$ species contacting weakly with the $\mathrm{SiO}_{2}$ supports, and the high-temperature shoulder peak around $700 \mathrm{~K}$ indicates the formation of hard-reducible $\mathrm{NiO}$ species bearing a strong interaction with the $\mathrm{SiO}_{2}$ support [39]. The hydrogen consumption peak of the $\mathrm{Ni}-\mathrm{Ru} / \mathrm{SiO}_{2}$ sample around $453 \mathrm{~K}$ can be attributed to the reduction of $\mathrm{RuO}_{2}\left(\mathrm{RuO}_{2}+\mathrm{H}_{2} \rightarrow \mathrm{Ru}+\mathrm{H}_{2} \mathrm{O}\right)$, which can be easily reduced at a comparatively low temperature. Additionally, this peak markedly overlaps with the subsequently large $\mathrm{H}_{2}$ consuming peaks, and the $\mathrm{NiO}$ reduction temperature obviously changes from $562 \mathrm{~K}$ to $549 \mathrm{~K}$, implying that active hydrogen species produced at the pre-generated $\mathrm{Ru}^{0}$ particles could easily spill into adjacent $\mathrm{NiO}$ sites to promote their reduction [33]. Therefore, the reducibility of the $\mathrm{Ni}-\mathrm{Ru} / \mathrm{SiO}_{2}$ catalysts is significantly increased, in contrast to the Ru-free $\mathrm{Ni} / \mathrm{SiO}_{2}$ samples. In accordance with the literature [40], the appearance of the overlapping 
hydrogen-consuming peaks indicates that the $\mathrm{RuO}_{2}$ species can closely interact with the $\mathrm{NiO}$ species, resulting in their high dispersion on the $\mathrm{Ni}-\mathrm{Ru} / \mathrm{SiO}_{2}$ sample. This effect may accelerate the reduction of $\mathrm{NiO}$ with a lower interaction. Moreover, it can be conjectured that the presence of $\mathrm{Ru}$ on the catalyst decreases the interactions between the small $\mathrm{NiO}$ particles and the supports; hence, improving the reducibility and facilitating the formation of bimetallic $\mathrm{Ni}-\mathrm{Ru}$ species.

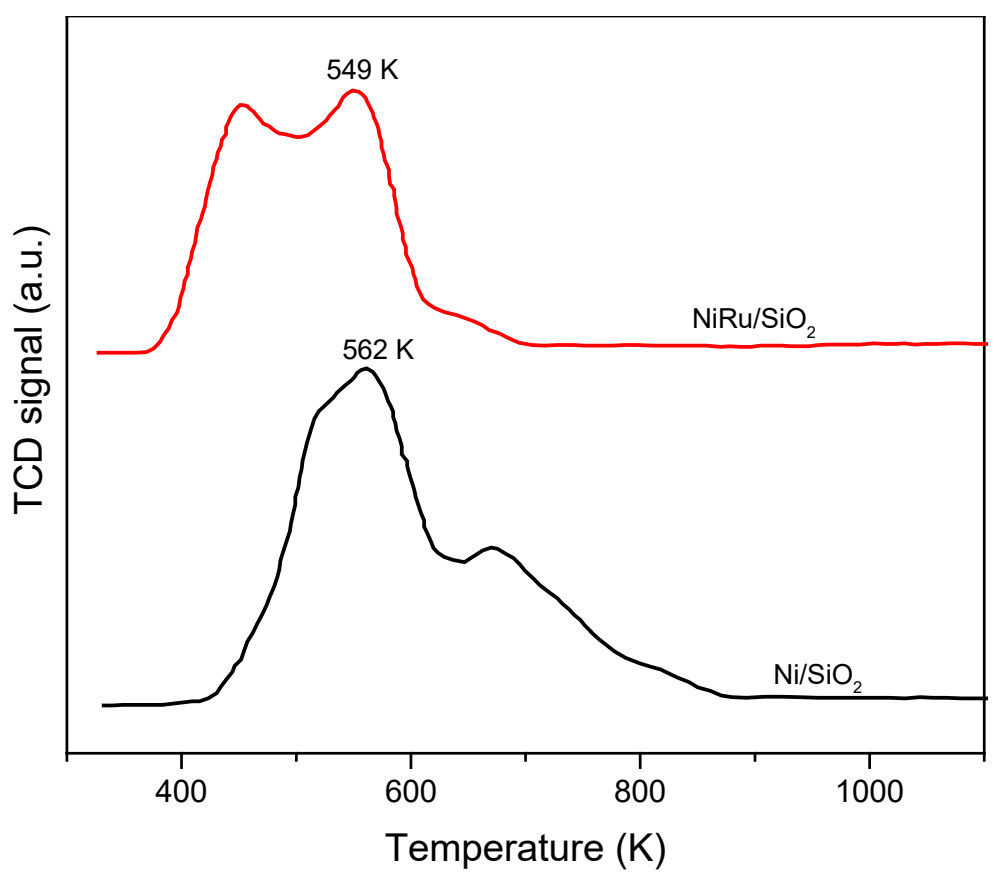

Figure 4. $\mathrm{H}_{2}$-TPR profiles of the $\mathrm{Ni} / \mathrm{SiO}_{2}$ and $\mathrm{Ni}-\mathrm{Ru} / \mathrm{SiO}_{2}$ samples.

\subsection{Catalytic Activity and Sulfur-Tolerant Performance}

The experimental data of the measured $\mathrm{HI}$ conversion rate versus the reaction time over the $\mathrm{Ni} / \mathrm{SiO}_{2}$ and $\mathrm{Ni}-\mathrm{Ru} / \mathrm{SiO}_{2}$ catalyst with different $\mathrm{H}_{2} \mathrm{SO}_{4}$ concentrations is presented in Figure 5a. The activity and poisoning experiments were investigated via a series of different conduct steps. Initially, a standard HI decomposition step with an HI solution ( $55 \mathrm{wt} \%$ ) is used in the absence of $\mathrm{H}_{2} \mathrm{SO}_{4}$ at $773 \mathrm{~K}$. Subsequently, various poisoning steps were executed, in which a solution at different $\mathrm{H}_{2} \mathrm{SO}_{4}$ concentrations $(500,1000$, 2000, and $3000 \mathrm{ppm}), \mathrm{HI}(55 \mathrm{wt} \%)$, and $\mathrm{H}_{2} \mathrm{O}$ were pumped in the test facility. Finally, at the end of the 800-min experiment, the standard HI decomposition step was repeated, closely following the poisoning steps, without changing the catalysts. These steps were continuously processed and monitored. Under the same experimental conditions of the standard $\mathrm{HI}$ decomposition, the $\mathrm{HI}$ conversion over $\mathrm{Ni}-\mathrm{Ru} / \mathrm{SiO}_{2}$ is strongly promoted from $16 \%$ to $20 \%$ compared to $\mathrm{Ni} / \mathrm{SiO}_{2}$. As is evident, the addition of $\mathrm{Ru}$ to the $\mathrm{Ni}$ catalysts significantly promotes the HI decomposition reaction. However, as can be seen in Figure 5a, significant changes in the $\mathrm{HI}$ conversion rate are observed over both catalysts in the poisoning steps, even at $500 \mathrm{ppm}$. It is to be noted that the activity of the $\mathrm{Ni} / \mathrm{SiO}_{2}$ is obviously weakened in the poisoning step (3000 ppm $\mathrm{H}_{2} \mathrm{SO}_{4}$ ), which was about a quarter of the activity prior to $\mathrm{H}_{2} \mathrm{SO}_{4}$ poisoning. Importantly, the deactivation effect was markedly reversible, indicating that the regeneration of some sulfur-poisoned sites may be achieved. In the repeated standard $\mathrm{HI}$ decomposition step without $\mathrm{H}_{2} \mathrm{SO}_{4}$ contamination, the activity of the $\mathrm{Ni} / \mathrm{SiO}_{2}$ becomes partly irreversible. Moreover, upon removal of $\mathrm{H}_{2} \mathrm{SO}_{4}$, the activity of the $\mathrm{Ni}-\mathrm{Ru} / \mathrm{SiO}_{2}$ catalysts returns to nearly the same level as prior to the $\mathrm{H}_{2} \mathrm{SO}_{4}$ exposure. The reversible deactivation is primarily based on competitive adsorption due to the sulfur species deposition on the catalyst surface [32]. It is concluded that $\mathrm{Ni}-\mathrm{Ru} / \mathrm{SiO}_{2}$ exhibits better activity in all the above steps. 

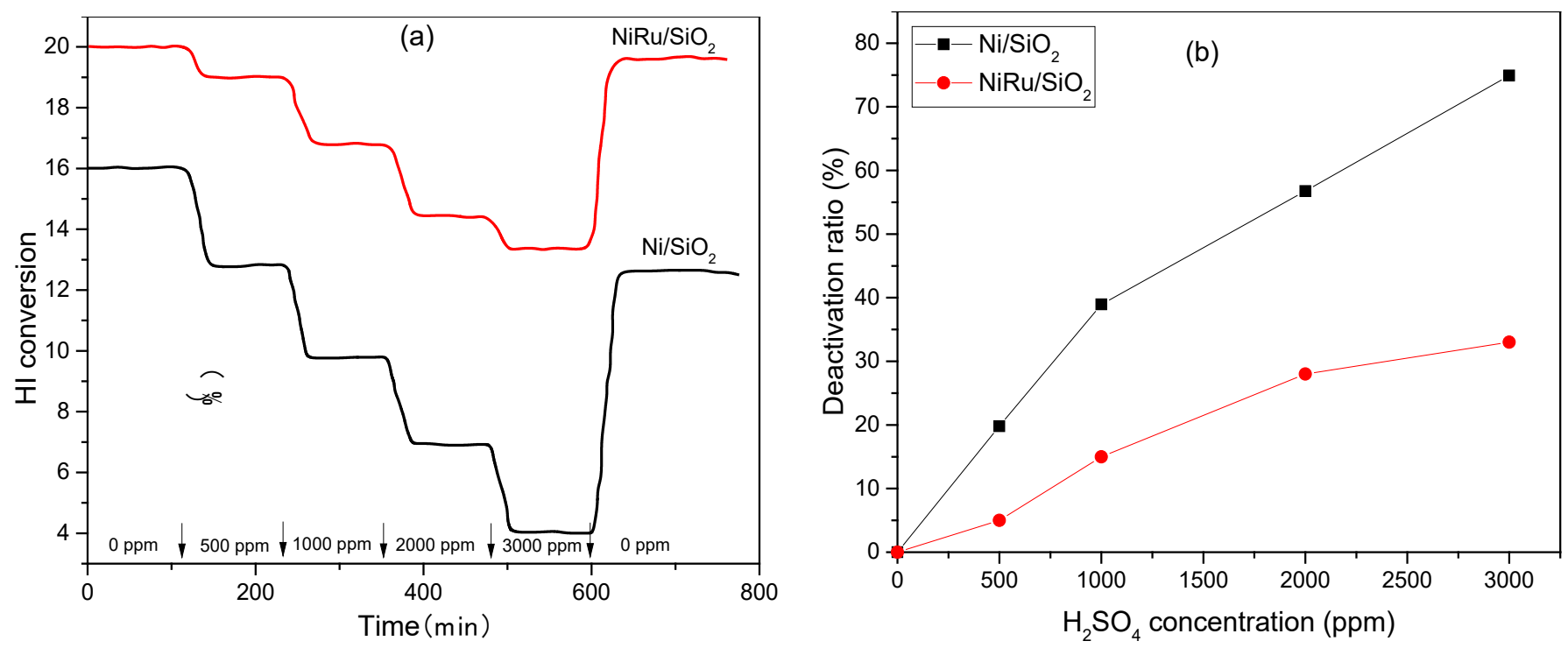

Figure 5. (a) Experimental $\mathrm{HI}$ conversion rate over $\mathrm{Ni} / \mathrm{SiO}_{2}$ and $\mathrm{Ni}-\mathrm{Ru} / \mathrm{SiO}_{2}$ measured in serial runs and (b) deactivation ratios at different $\mathrm{H}_{2} \mathrm{SO}_{4}$ concentrations.

Figure $5 \mathrm{~b}$ shows the deactivation ratios at the different $\mathrm{H}_{2} \mathrm{SO}_{4}$ concentrations. Notably, the deactivation rates are gradually varied, and this can be due to the $\mathrm{H}_{2} \mathrm{SO}_{4}$ concentration gradients and the possible loss of the catalyst activities. Meanwhile, $\mathrm{Ni} / \mathrm{SiO}_{2}$ has more severe deactivation compared to $\mathrm{Ni}-\mathrm{Ru} / \mathrm{SiO}_{2}$. This indicates that $\mathrm{Ni}-\mathrm{Ru} / \mathrm{SiO}_{2}$ could resist the sulfur poisoning. These results show that the addition of $\mathrm{Ru}$ to the $\mathrm{Ni} / \mathrm{SiO}_{2}$ catalyst promotes the stability and activity of the catalysts.

\subsection{Characterization of the Deactivated Catalysts}

The crystal structures of the deactivated catalysts after exposure to the $\mathrm{H}_{2} \mathrm{SO}_{4}$ - containing $\mathrm{HI}$ solution are observed by $\mathrm{XRD}$, and the results are presented in Figure 6. Different from the $\mathrm{Ni} / \mathrm{SiO}_{2}$, the $\mathrm{Ni}-\mathrm{Ru} / \mathrm{SiO}_{2}$ catalyst has a small peak around $28.09,35.11$ and $54.38^{\circ}$, which is the diffraction peak of $\mathrm{RuO}_{2}$ [JCPDS No. 70-2662]. It also has an NiO crystal peak around $39.26,43.29$ and $62.89^{\circ}$ [JCPDS No. 89-5881], and exhibits the characteristic diffraction peak of $\mathrm{Ni}_{2} \mathrm{O}_{3}\left(2 \theta \approx 39.13\right.$ and $\left.51.59^{\circ}\right)$ [JCPDS No. 14-0481]. It is possible to conclude that the appearance of the small amounts of $\mathrm{RuO}_{2}$ and nickel oxide reflections in XRD patterns can be explained by contact of discharged samples with air, since such oxides could not be stable in the presence of hydrogen in the HI decomposition tests. In addition, the peak of the $\mathrm{Ni}_{2} \mathrm{SiO}_{4}$ phase is observed for the $\mathrm{Ni} / \mathrm{SiO}_{2}$ catalyst [JCPDS No. 74-0563], which shows that some nickel silicate has formed on the $\mathrm{Ni} / \mathrm{SiO}_{2}$ sample. This indicates that the Ni species strongly interacts with the $\mathrm{SiO}_{2}$ supports, as the silica and nickel oxide gradually transform to nickel silicate during the $\mathrm{H}_{2} \mathrm{SO}_{4}$ poisoning process.

On the other hand, after long reaction times, the reflections of cristobalite [JCPDS No. 75-0923] appear in diffraction patterns of the poisoned $\mathrm{Ni} / \mathrm{SiO}_{2}$ and $\mathrm{Ni}-\mathrm{Ru} / \mathrm{SiO}_{2}$ catalysts while being absent in the patterns of fresh initial samples. This indicates that the presence of sulfuric acid along with steam in reaction conditions facilitates silica crystallization. Such crystallization weakens the interaction of support with $\mathrm{Ni}$ and $\mathrm{Ru}$, resulting in the aggregation of catalysts. The calculated crystal diameters of the poisoned samples are larger than the fresh catalysts. These observations reveal that trace $\mathrm{H}_{2} \mathrm{SO}_{4}$ contamination in the $\mathrm{HI}$ contributed to the sintering of $\mathrm{Ni}^{0}$ particles and their aggregation, while no $\mathrm{NiSx}$ crystals appear on the catalysts.

XPS is used to detect the surface composition of the catalysts and provide further evidence of their electronic structures. Nevertheless, there is no $S$ element existing based on the XPS analysis for each poisoned catalyst. Therefore, the oxidation state on the $\mathrm{Ni}$ surface is the only concern. At the $\mathrm{Ni} 2 \mathrm{p}_{3 / 2}$ level of the fresh $\mathrm{Ni}-\mathrm{Ru} / \mathrm{SiO}_{2}$ and $\mathrm{Ni} / \mathrm{SiO}_{2}$ 
catalysts (as shown in Figure 7), the prominent asymmetric peaks of $\mathrm{NiO}$ species appear at $855 \mathrm{eV}$, accompanied by the obvious shoulder peaks. These results are consistent with the TPR results (Figure 2).

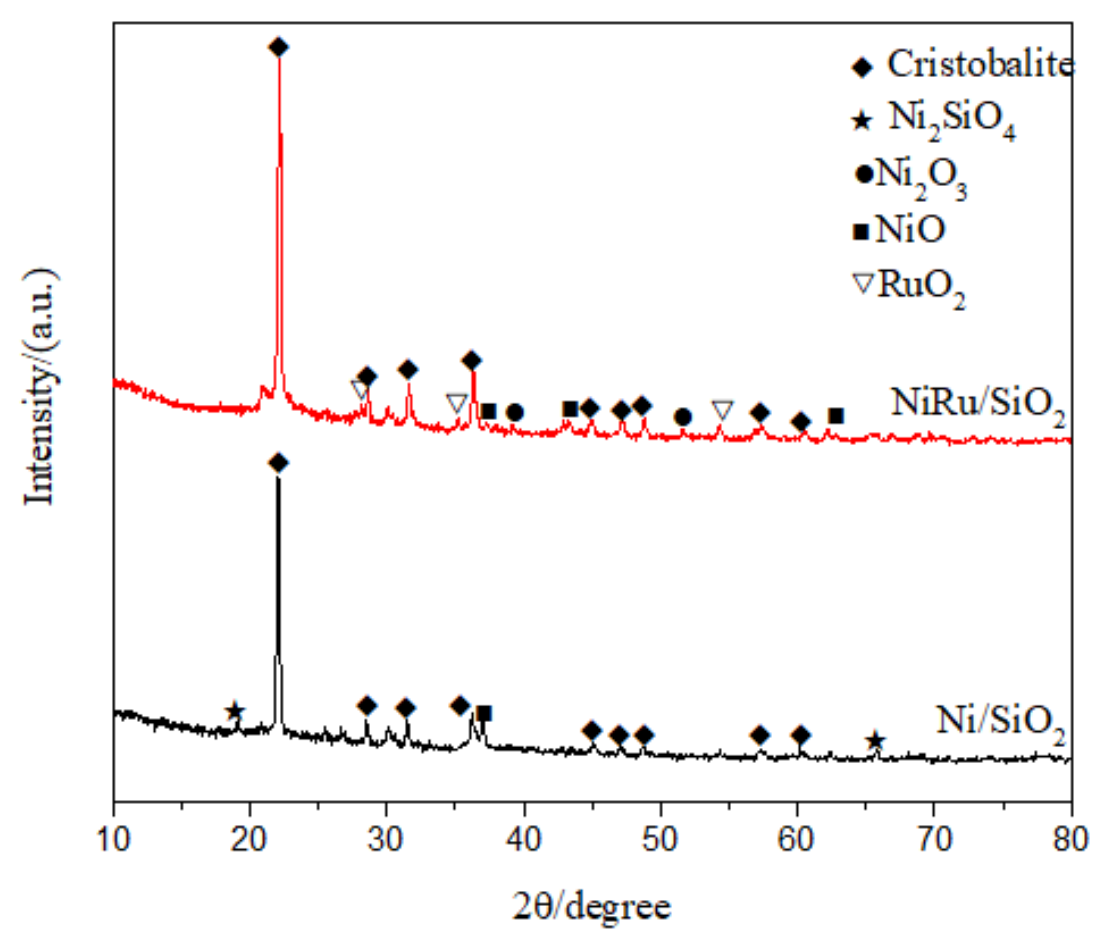

Figure 6. XRD patterns of the poisoned $\mathrm{Ni} / \mathrm{SiO}_{2}$ and $\mathrm{Ni}-\mathrm{Ru} / \mathrm{SiO}_{2}$ catalysts after exposure to 3000 ppm $\mathrm{H}_{2} \mathrm{SO}_{4}$.

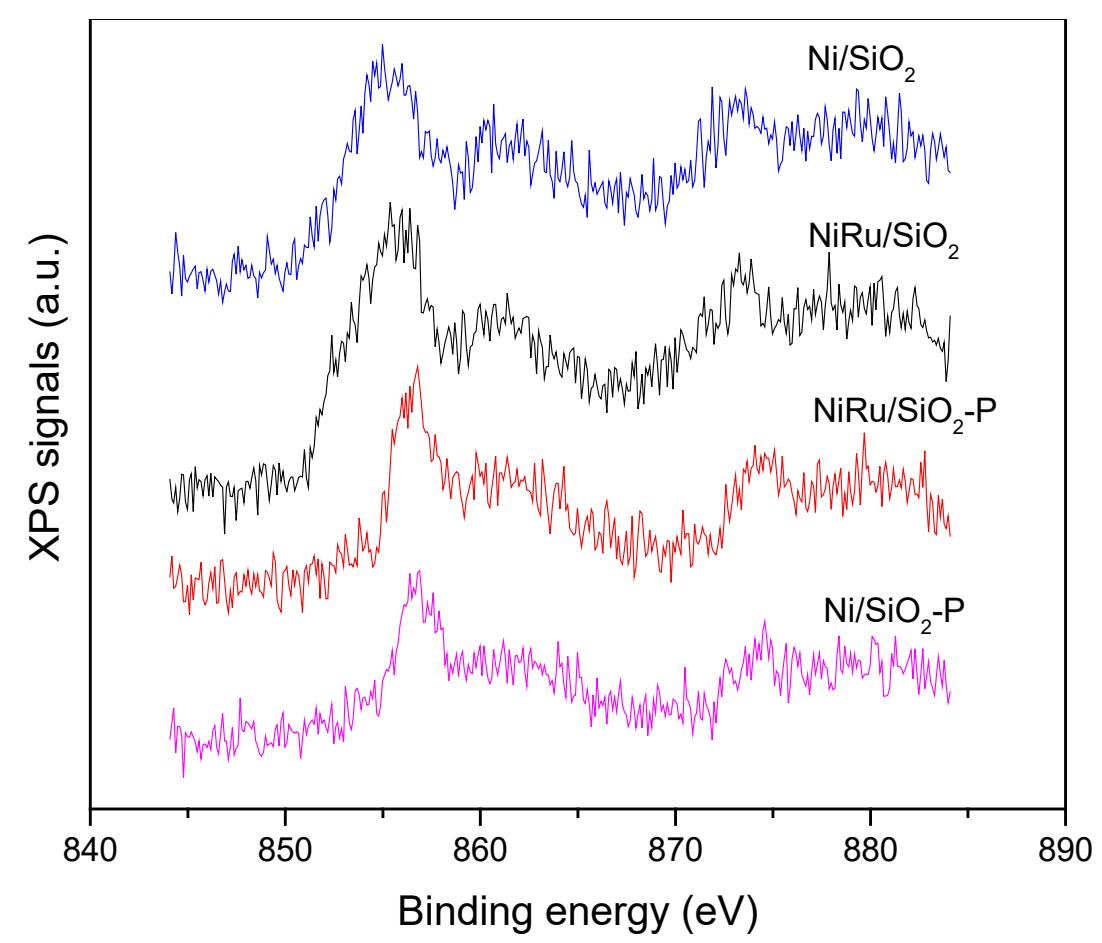

Figure 7. XPS measurements for $3000 \mathrm{ppm} \mathrm{H}_{2} \mathrm{SO}_{4}$ poisoned and fresh $\mathrm{Ni} / \mathrm{SiO}_{2}$ and $\mathrm{Ni}-\mathrm{Ru} / \mathrm{SiO}_{2}$ catalysts in the $\mathrm{Ni} 2 \mathrm{p}$ region. 
Additionally, the shoulder peak at $852 \mathrm{eV}$ is attributed to the $\mathrm{Ni}^{0}$ species [41]. It is noted that the poisoned $\mathrm{Ni} / \mathrm{SiO}_{2}$ and $\mathrm{Ni}-\mathrm{Ru} / \mathrm{SiO}_{2}$ catalysts consists of the nickel in higher oxidation states (e.g., $\mathrm{Ni}^{2+}$ ), possibly in oxidic or hydrated form, with small amounts of the $\mathrm{Ni}^{0}$. It confirms that nickel was relatively easy to be oxidized in the presence of oxygen if no precautions are taken to prevent exposure of the discharged catalysts to air.

\subsection{Adsorption Modeling}

Although the activity loss in the presence of $\mathrm{H}_{2} \mathrm{SO}_{4}$ for the $\mathrm{HI}$ decomposition reaction is primarily due to competitive sulfur species adsorption at the active sites, the mechanism of the reactions between the sulfur-containing contaminants remains unclear, and the bimetallic effect may be complex. It is desirable to gain a further mechanism understanding of the chemical composition and particle structure in regard to competitive sulfur species adsorption, as this may contribute to the further exploration and the development of highly sulfur-tolerant Ni-based catalysts. Accordingly, computational modeling is used to assess the adsorption energies of $\mathrm{HI}$ and $\mathrm{S}$ on the bimetallic and Ni-based surfaces. In particular, dissociative sulfur-species adsorption has been shown to constantly happen on the surfaces or clusters of transition metals [42]. Therefore, the various structures of tetrahedral clusters are focused on modeling the Ni and bimetallic surfaces. Furthermore, the adsorption of $\mathrm{HI}$ on the $\mathrm{Ru}, \mathrm{Ni}-\mathrm{Ru}$, and $\mathrm{Ni}$ clusters are explored. Figure 8a illustrates that the adsorption of $\mathrm{HI}$ on the Ni clusters appears to be much less significant than that on the $\mathrm{Ni}-\mathrm{Ru}$ and $\mathrm{Ru}$ clusters. The $\mathrm{HI}$ absorption in the presence of $\mathrm{Ru}$ is much stronger, and this may be the major reason that $\mathrm{Ni}-\mathrm{Ru} / \mathrm{SiO}_{2}$ demonstrates a better activity than that of $\mathrm{Ni} / \mathrm{SiO}_{2}$.

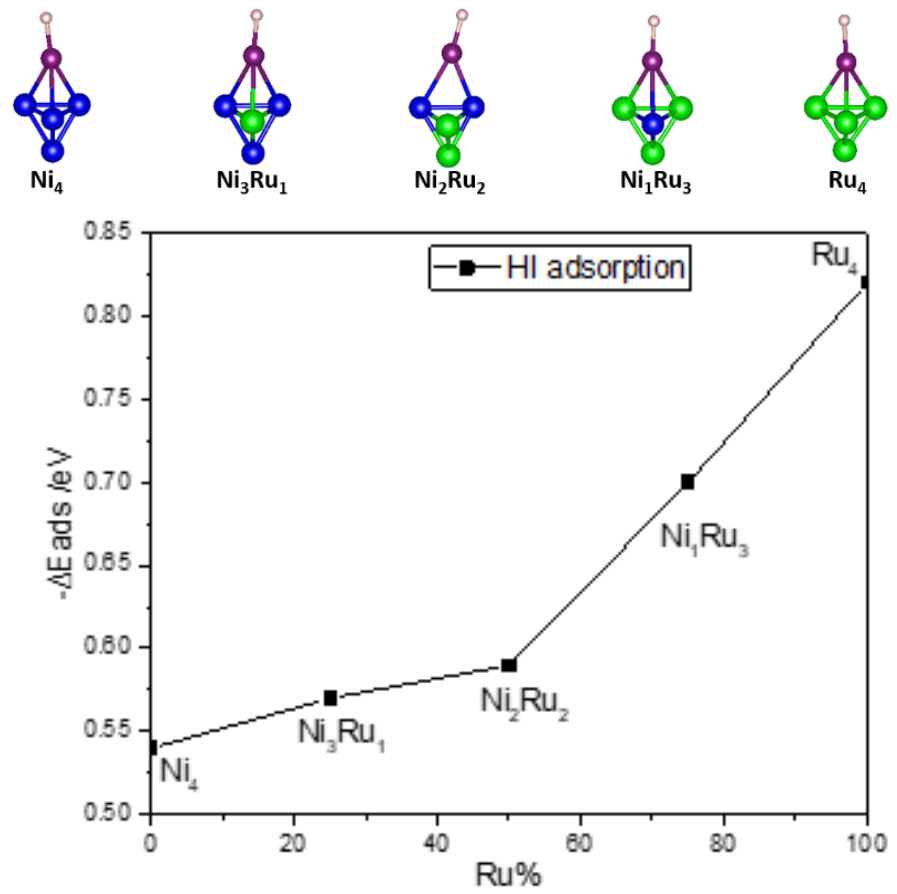

(a)
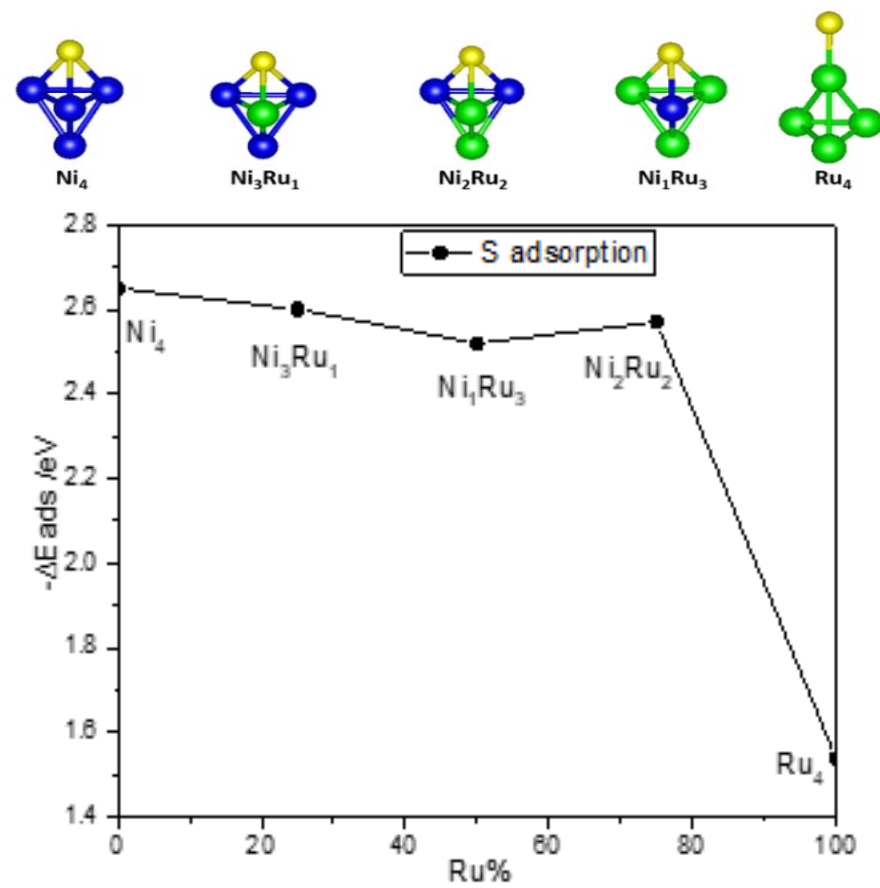

(b)

Figure 8. The most probable adsorption model and energies of (a) $\mathrm{HI}$ adsorbed onRu $\mathrm{u}_{4}, \mathrm{Ni}_{1} \mathrm{Ru}_{3}, \mathrm{Ni}_{2} \mathrm{Ru}_{2}, \mathrm{Ni}_{3} \mathrm{Ru}_{1}$, andNi clusters, and (b) $\mathrm{S}$ adsorbed on $\mathrm{Ru}_{4}, \mathrm{Ni}_{1} \mathrm{Ru}_{3}, \mathrm{Ni}_{2} \mathrm{Ru}_{2}, \mathrm{Ni}_{3} \mathrm{Ru}_{1}$, and $\mathrm{Ni}_{4}$ clusters.

Figure $8 \mathrm{~b}$ presents the adsorption energies and the most stable geometries of $\mathrm{S}$ adsorption on the clusters. The differences in sulfur adsorption energies among the five kinds of clusters provides insights into the $\mathrm{S}$ resistance of the bimetallic catalysts. The adsorption energy of $\mathrm{S}$ on the pure $\mathrm{Ni}_{4}$ surface is much more significant than on the Ru-containing clusters, suggesting that $\mathrm{S}$ deposition is lower on Ru compared to the Ni catalysts. Such adsorption $\mathrm{S}$ coverage will block the active sites and accelerate catalyst sintering. The 
$\mathrm{Ru}_{4}$ clusters show the lowest adsorption energy, demonstrating that $\mathrm{S}$ adsorption is less competitive on the $\mathrm{Ru}$ clusters than on the $\mathrm{Ni}-\mathrm{Ru}$ or Ni clusters. Compared with the pure $\mathrm{Ni}_{4}$ clusters, the higher sulfur tolerance of the $\mathrm{Ni}-\mathrm{Ru}$ binary metal may be explained by the weaker $S$ blocking. Thus, calculation results of the $S$ adsorption are consistent with the above experimental investigations, as no NiSx crystals are observed experimentally on the $\mathrm{Ni}$ or Ni-Ru catalysts. The addition of Ru promotes activity and sulfur resistance of the catalyst for $\mathrm{HI}$ decomposition by reducing the $\mathrm{S}$ adsorption, as evidenced by the theoretical modeling analyses. Consequently, the $\mathrm{Ni}-\mathrm{Ru} / \mathrm{SiO}_{2}$ catalyst can maintain a more significant activity and demonstrate increased sulfur-tolerance for $\mathrm{HI}$ decomposition.

Based on the previous analysis, it can be found that the addition of Ru can form a specific interaction with $\mathrm{NiO}$ and promote the reduction of $\mathrm{NiO}$ particles. The specific catalytic mechanism is shown in Figure 9. During the formation process of the $\mathrm{Ni}-\mathrm{Ru} / \mathrm{SiO}_{2}$ catalyst, $\mathrm{RuO}_{2}$ is firstly reduced to $\mathrm{Ru}$ metal particles at a relatively low temperature, and gradually correlates with $\mathrm{NiO}$ particles to form a NiO-Ru bimetallic structure. In the meantime, Ru can also activate $\mathrm{H}_{2}$ and easily produces a hydrogen overflow phenomenon, which promotes the formation of a Ni-Ru bimetallic structure. Additionally, the active hydrogen species generated at Ru particles can easily spill into the adjacent $\mathrm{NiO}$ particles, thus promoting their reduction reaction. According to the theoretical simulation results, the presence of $\mathrm{Ru}$ can enhance the $\mathrm{HI}$ adsorption over $\mathrm{Ni}-\mathrm{Ru} / \mathrm{SiO}_{2}$ catalyst. This makes the catalytic activity of $\mathrm{Ni}-\mathrm{Ru} / \mathrm{SiO}_{2}$ catalyst better than that of $\mathrm{Ni} / \mathrm{SiO}_{2}$ catalyst. The $\mathrm{Ni} / \mathrm{SiO}_{2}$ catalyst does not show enhanced sulfur resistance since single metal $\mathrm{Ni}$ or $\mathrm{NiO}$ particles do not reduce the adsorption of sulfur while $\mathrm{Ni}-\mathrm{Ru} / \mathrm{SiO}_{2}$ catalyst offers good sulfur resistance.

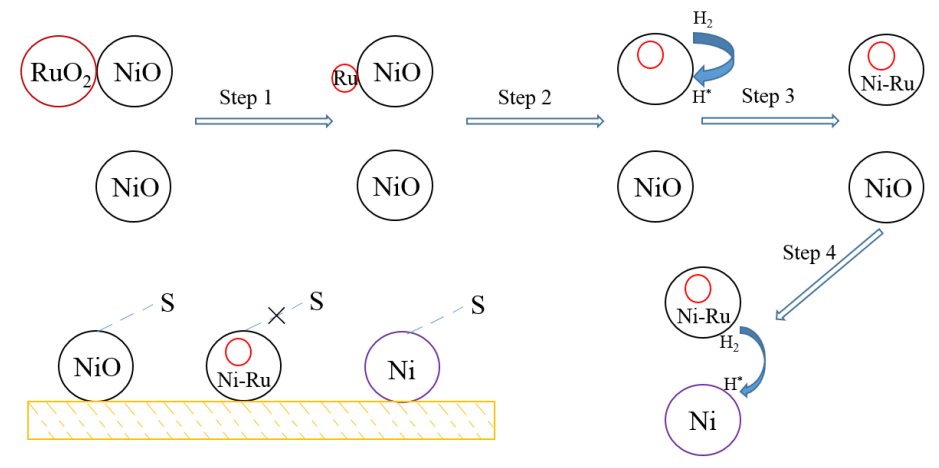

Figure 9. Mechanism schematic of $\mathrm{Ni}-\mathrm{Ru} / \mathrm{SiO}_{2}$ catalyst.

\section{Conclusions}

The effects of $\mathrm{Ru}$ addition on $\mathrm{HI}$ conversion and sulfur adsorption of $\mathrm{Ni}$ and $\mathrm{Ni}-\mathrm{Ru}$ catalysts supported on $\mathrm{SiO}_{2}$ have been investigated in this study. TPR, TEM-EDX, XRD, and XPS techniques were used to observe their physicochemical properties. The experimental trends in activity and sulfur tolerance are consistent with the theoretical modeling, with the catalytic activities existing in the order $\mathrm{Ni} / \mathrm{SiO}_{2}<\mathrm{Ni}-\mathrm{Ru} / \mathrm{SiO}_{2}$, as the addition of $\mathrm{Ru}$ to a Ni catalyst can promote $\mathrm{HI}$ adsorption. Modeling calculations were applied to identify bimetallic Ni-Ru surfaces with lower sulfur adsorption and to enhance $\mathrm{HI}$ adsorption energies. In the presence of trace $S$ species, the specific $S$ coverage on the catalysts blocked the active sites and enhanced sintering. The adsorption modeling results are consistent with the experiments for the supported bimetallic $\mathrm{Ni}-\mathrm{Ru}$ catalysts, demonstrating that sulfur resistance for the $\mathrm{HI}$ decomposition reaction is promoted by the bimetallic $\mathrm{Ni}-\mathrm{Ru}$ catalysts, which can reduce the competitive adsorption of sulfur and minimize the effect of sulfur poisoning. The activity and sulfur tolerance of the catalysts are highly dependent on $\mathrm{HI}$ and $\mathrm{S}$ adsorption. The presence of $\mathrm{Ru}$ can increase the $\mathrm{HI}-\mathrm{Ni}^{0}$ interaction and reduce $\mathrm{S}$ adsorption. Thus, a remarkable improvement in catalytic activity and sulfur tolerance of bimetallic $\mathrm{Ni}-\mathrm{Ru}$ in $\mathrm{HI}$ decomposition was obtained, providing new insights for maintaining more significant activity during $\mathrm{HI}$ decomposition in the presence of sulfur. 
Author Contributions: L.W.: Investigation, Methodology, Formal analysis, Writing-original draft preparation, writing—review and editing. K.Z.: Software, Methodology, Visualization, Supervision. Y.Q.: Formal analysis, Investigation. H.C.: Investigation, project administration. J.W.: validation, Z.W.: Conceptualization, Data curation, Formal analysis, project administration. All authors have read and agreed to the published version of the manuscript.

Funding: This research was funded by the Program of the Innovative Research Groups of the National Natural Science Foundation of China (No. 51621005).

Institutional Review Board Statement: Not applicable.

Informed Consent Statement: Not applicable.

Data Availability Statement: The authors declare that the main data supporting the findings of this study are available within the article file. Extra data are available from the corresponding author upon request.

Acknowledgments: This work was supported by the Program of the Innovative Research Groups of the National Natural Science Foundation of China (51621005) and Introducing Talents of Discipline to Universities (B08026).

Conflicts of Interest: The authors declare no conflict of interest. The funders have no role in the design of the study; in the collection, analyses, or interpretation of data; in the writing of the manuscript, or in the decision to publish the results.

\section{References}

1. Singhania, A.; Bhaskarwar, A.N. $\mathrm{TiO}_{2}$ as a catalyst for hydrogen production from hydrogen-iodide in thermo-chemical watersplitting sulfur-iodine cycle. Fuel 2018, 221, 393-398. [CrossRef]

2. Ying, Z.; Zheng, X.; Cui, G. Detailed kinetic study of the electrochemical Bunsen reaction in the sulfur-iodine cycle for hydrogen production. Energy Convers. Manag. 2016, 115, 26-31. [CrossRef]

3. Dincer, I.; Balta, M.T. Potential thermochemical and hybrid cycles for nuclear-based hydrogen production. Int. J. Energy Res. 2011, 35, 123-137. [CrossRef]

4. Singhania, A.; Krishnan, V.V.; Bhaskarwar, A.N.; Bhargava, B.; Parvatalu, D. Hydrogen-iodide decomposition over PdCeO 2 nanocatalyst for hydrogen production in sulfur-iodine thermochemical cycle. Int. J. Hydrogen Energy 2018, 43, 3886-3891. [CrossRef]

5. Ying, Z.; Zheng, X.; Zhang, Y.; Cui, G. Kinetic analysis of Bunsen reaction with HI existence in the thermochemical sulfur-iodine cycle for hydrogen production. Appl. Therm. Eng. 2018, 129, 41-49. [CrossRef]

6. Tyagi, D.; Varma, S.; Bharadwaj, S. Pt/graphite catalyst for hydrogen generation by HI decomposition reaction in S-I thermochemical cycle. Int. J. Energy Res. 2015, 39, 2008-2018. [CrossRef]

7. Bai, S.; Wang, L.; Han, Q.; Zhang, P.; Chen, S.; Meng, X.; Xu, J. Experimental study on the purification of HIx phase in the iodine-sulfur thermochemical hydrogen production process. Int. J. Hydrogen Energy 2013, 38, 29-35. [CrossRef]

8. Tyagi, D.; Varma, S.; Bharadwaj, S.R. Mesoporous Carbon Supported Platinum Nanocatalyst: Application for Hydrogen Production by HI Decomposition Reaction in S-I Cycle. J. Nanosci. Nanotechnol. 2017, 17, 2177-2184. [CrossRef]

9. Wang, L.; Imai, Y.; Tanaka, N.; Kasahara, S.; Kubo, S.; Onuki, K. Thermodynamic considerations on the purification of $\mathrm{H}_{2} \mathrm{SO}_{4}$ and HIx phases in the iodine-sulfur hydrogen production process. Chem. Eng. Commun. 2012, 199, 165-177. [CrossRef]

10. Dokiya, M.; Kameyama, T.; Fukuda, K.; Kotera, Y. The study of thermochemical hydrogen preparation. III. An oxygen-evolving step through the thermal splitting of sulfuric acid. Bull. Chem. Soc. Jpn. 1977, 50, 2657-2660. [CrossRef]

11. Le Duigou, A.; Borgard, J.-M.; Larousse, B.; Doizi, D.; Allen, R.; Ewan, B.C.; Priestman, G.H.; Elder, R.; Devonshire, R.; Ramos, V. HYTHEC: An EC funded search for a long term massive hydrogen production route using solar and nuclear technologies. Int. J. Hydrogen Energy 2007, 32, 1516-1529. [CrossRef]

12. Hinshelwood, C.N.; Prichard, C.R. CCVII-The relation of homogeneous to catalysed reactions. The catalytic decomposition of hydrogen iodide on the surface of gold. J. Chem. Soc. Trans. 1925, 127, 1552-1559. [CrossRef]

13. Hinshelwood, C.N.; Burk, E.R. CCCCII-The relation of homogeneous to catalysed reactions. The catalytic decomposition of hydrogen iodide on the surface of platinum. J. Chem. Soc. Trans. 1925, 127, 2896-2900. [CrossRef]

14. Zhang, Y.W.; Wang, Z.H.; Zhou, J.H.; Cen, K.F. Ceria as a catalyst for hydrogen iodide decomposition in sulfur-iodine cycle for hydrogen production. Int. J. Hydrogen Energy 2009, 34, 1688-1695. [CrossRef]

15. Zhang, Y.; Wang, Z.; Zhou, J.; Liu, J.; Cen, K. Experimental study of $\mathrm{Ni} / \mathrm{CeO}_{2}$ catalytic properties and performance for hydrogen production in sulfur-iodine cycle. Int. J. Hydrogen Energy 2009, 34, 5637-5644. [CrossRef]

16. Fu, G.S.; He, Y.; Zhang, Y.W.; Zhu, Y.Q.; Wang, Z.H.; Cen, K.F. Catalytic performance and durability of Ni/AC for HI decomposition in sulfur-iodine thermochemical cycle for hydrogen production. Energ. Convers. Manag. 2016, 117, 520-527. [CrossRef] 
17. Fu, G.; Wang, Z.; Zhang, Y.; Huang, Z.; Liu, J.; Zhou, J.; Cen, K. Effect of raw material sources on activated carbon catalytic activity for $\mathrm{HI}$ decomposition in the sulfur-iodine thermochemical cycle for hydrogen production. Int. J. Hydrogen Energy 2016, 41, 7854-7860. [CrossRef]

18. Zhang, Y.; Wang, Z.; Zhou, J.; Liu, J.; Cen, K. Effect of preparation method on platinum-ceria catalysts for hydrogen iodide decomposition in sulfur-iodine cycle. Int. J. Hydrogen Energy 2008, 33, 602-607. [CrossRef]

19. Zhang, Y.; Wang, Z.; Zhou, J.; Liu, J.; Cen, K. Catalytic decomposition of hydrogen iodide over pre-treated $\mathrm{Ni} / \mathrm{CeO}_{2}$ catalysts for hydrogen production in the sulfur-iodine cycle. Int. J. Hydrogen Energy 2009, 34, 8792-8798. [CrossRef]

20. Zhang, Y.; Zhou, J.; Wang, Z.; Liu, J.; Cen, K. Influence of the oxidative/reductive treatments on Pt/CeO 2 catalyst for hydrogen iodide decomposition in sulfur-iodine cycle. Int. J. Hydrogen Energy 2008, 33, 2211-2217. [CrossRef]

21. Zhang, Y.; Fu, G.; Wang, Z.; Lin, X.; Wang, L.; Kuang, M.; Whiddon, R.; Cen, K. HI Decomposition over carbon-based and Ni-impregnated catalysts of the sulfur-iodine cycle for hydrogen production. Ind. Eng. Chem. Res. 2015, 54, 1498-1504. [CrossRef]

22. Favuzza, P.; Felici, C.; Lanchi, M.; Liberatore, R.; Mazzocchia, C.; Spadoni, A.; Tarquini, P.; Tito, A. Decomposition of hydrogen iodide in the S-I thermochemical cycle over Ni catalyst systems. Int. J. Hydrogen Energy 2009, 34, 4049-4056. [CrossRef]

23. Favuzza, P.; Felici, C.; Nardi, L.; Tarquini, P.; Tito, A. Kinetics of hydrogen iodide decomposition over activated carbon catalysts in pellets. Appl. Catal. B Environ. 2011, 105, 30-40. [CrossRef]

24. Kasahara, S.; Iwatsuki, J.; Takegami, H.; Tanaka, N.; Noguchi, H.; Kamiji, Y.; Onuki, K.; Kubo, S. Current R\&D status of thermochemical water splitting iodine-sulfur process in Japan Atomic Energy Agency. Int. J. Hydrogen Energy 2017, 42, 1347713485. [CrossRef]

25. Zhang, Y.; Lin, J.; Wang, Z.; Wang, R.; Cen, K. Study of the mechanism of the catalytic decomposition of hydrogen iodide (HI) over carbon materials for hydrogen production. Int. J. Hydrogen Energy 2017, 42, 4977-4986. [CrossRef]

26. Singhania, A. Catalytic Decomposition of Hydrogen-Iodide Over Nanocrystalline Ceria Promoted by Transition Metal Oxides for Hydrogen Production in Sulfur-Iodine Thermo-Chemical Cycle. Catal. Lett. 2018, 148, 1416-1422. [CrossRef]

27. Parisi, M.; Giaconia, A.; Sau, S.; Spadoni, A.; Caputo, G.; Tarquini, P. Bunsen reaction and hydriodic phase purification in the sulfur-iodine process: An experimental investigation. Int. J. Hydrogen Energy 2011, 36, 2007-2013. [CrossRef]

28. Guo, H.; Zhang, P.; Bai, Y.; Wang, L.; Chen, S.; Xu, J. Continuous purification of $\mathrm{H}_{2} \mathrm{SO}_{4}$ and $\mathrm{HI}$ phases by packed column in IS process. Int. J. Hydrogen Energy 2010, 35, 2836-2839. [CrossRef]

29. Sakurai, M.; Nakajima, H.; Onuki, K.; Shimizu, S. Investigation of 2 liquid phase separation characteristics on the iodine-sulfur thermochemical hydrogen production process. Int. J. Hydrogen Energy 2000, 25, 605-611. [CrossRef]

30. Ying, B.; Zhang, P.; Hanfei, G.; Songzhe, C.; Laijun, W.; Jingming, X. Purification of sulfuric and hydriodic acids phases in the iodine-sulfur process. Chin. J. Chem. Eng. 2009, 17, 160-166.

31. Sheng, Z.; Yufeng, H.; Jianming, X.; Xiaoming, W.; Weiping, $\mathrm{L} . ~^{\mathrm{SO}_{2}}$ poisoning and regeneration of $\mathrm{Mn}-\mathrm{Ce} / \mathrm{TiO} 2$ catalyst for low temperature NOx reduction with $\mathrm{NH}_{3}$. J. Rare Earths 2012, 30, 676-682. [CrossRef]

32. Wang, L.; Zhu, Y.; Fu, G.; He, Y.; Zhang, Y.; Wang, Z. $\mathrm{H}_{2} \mathrm{SO}_{4}$ poisoning of Ru-based and Ni-based catalysts for HI decomposition in SulfurIodine cycle for hydrogen production. Int. J. Hydrogen Energy 2019, 44, 9771-9778. [CrossRef]

33. Yuan, C.; Nan, Y.; Wang, X.; Wang, J.; Lv, D.; Li, X. The $\mathrm{SiO}_{2}$ supported bimetallic Ni-Ru particles: A good sulfur-tolerant catalyst for methanation reaction. Chem. Eng. J. 2015, 260, 1-10. [CrossRef]

34. Kresse, G.; Furthmüller, J. Efficient iterative schemes for ab initio total-energy calculations using a plane-wave basis set. Phys. Rev. B 1996, 54, 11169-11186. [CrossRef]

35. Kresse, G.; Hafner, J. Ab initio. Phys. Rev. B 1994, 49, 14251-14269. [CrossRef]

36. Blöchl, P.E. Projector augmented-wave method. Phys. Rev. B 1994, 50, 17953-17979. [CrossRef]

37. Perdew, J.P.; Burke, K.; Ernzerhof, M. Generalized Gradient Approximation Made Simple. Phys. Rev. Lett. 1996, 77, 3865-3868. [CrossRef]

38. Monkhorst, H.J.; Pack, J.D. Special points for Brillouin-zone integrations. Phys. Rev. B 1976, 13, 5188. [CrossRef]

39. Burattin, P.; Che, M.; Louis, C. Characterization of the Ni(II) phase formed on silica upon deposition-precipitation. J. Phys. Chem. B 1997, 101, 7060-7074. [CrossRef]

40. Yao, N.; Ma, H.; Shao, Y.; Yuan, C.; Lv, D.; Li, X. Effect of cation-oligomer interactions on the size and reducibility of NiO particles on $\mathrm{NiRu} / \mathrm{SiO}_{2}$ catalysts. J. Mater. Chem. 2011, 21, 17403-17412. [CrossRef]

41. Czekaj, I.; Loviat, F.; Raimondi, F.; Wambach, J.; Biollaz, S.; Wokaun, A. Characterization of surface processes at the Ni-based catalyst during the methanation of biomass-derived synthesis gas: X-ray photoelectron spectroscopy (XPS). Appl. Catal. A Gen. 2007, 329, 68-78. [CrossRef]

42. Alfonso, D.R. First-principles studies of $\mathrm{H}_{2} \mathrm{~S}$ adsorption and dissociation on metal surfaces. Surf. Sci. 2008, 602, $2758-2768$. [CrossRef] 